\title{
The neonatal intubation causes defects in primary teeth of premature infants
}

\author{
Norma Suely Falcao de Oliveira Melo ${ }^{a}$, Regina Paula Guimaraes Vieira Cavalcante da Silvab, \\ Antonio Adilson Soares de Lima ${ }^{a}$
}

\begin{abstract}
Aim. This study aimed to evaluate the relationship between intubation during the neonatal period and enamel defects in primary teeth of preterm infants. It was an observational, prospective, analytical and sampling of convenience. We selected 157 children who had average birth weight of $1656.3 \pm 627.8 \mathrm{~g}$, gestational age of $31.7 \pm 2.7$ weeks and the examination of chronological age $2.2 \pm 0.6$ years old.

Methods. Clinical examination of the oral cavity showed that the frequency of enamel defects was higher (86.3\%) among children intubated when compared to non-intubated children (13.7\%). The enamel defects was found to be inversely proportional to gestational age. The intubation time was related to the probability of occurrence of DDE $(P<0.001)$, in other words, the greater the number of days intubated, the greater the chance of DDE. In children intubated, hypoplasia mainly affected the upper teeth on the left side of the mouth.

Conclusion. Tracheal intubation in the neonatal period is the main cause of enamel defects in primary teeth of children born preterm. The longer the duration of intubation, the greater the chance of developing dental enamel defect. The area of action during movement of the laryngoscope toggle corresponds to the region most affected by tooth enamel hypoplasia in children intubated, upper right central incisor, lateral incisor and upper left.
\end{abstract}

Key words: prematurity, tracheal intubation, enamel defects

Received: August 21, 2012; Accepted: January 17, 2013; Available online: February 26, 2013

http://dx.doi.org/10.5507/bp.2013.004

${ }^{a}$ Department of Stomatology, School of Dentistry, Universidade Federal do Parana - UFPR, Curitiba-PR, Brazil

${ }^{b}$ Department of Pediatrics, School of Medicine, Universidade Federal do Parana - UFPR, Curitiba-PR, Brazil

Corresponding author: Norma Suely Falcao de Oliveira Melo, e-mail: normamel@ufpr.br

\section{INTRODUCTION}

The early termination of pregnancy and the resulting organic and functional immaturity are crucial to the high morbidity and mortality in premature newborns. Prematurity is immediate or late manifestations of the growth and development of children ${ }^{1-3}$, and the survival of premature infants one of the most important challenges of neonatology 4,5 .

New technologies used in the neonatal intensive care led to improvements in the quality of perinatal care of preterm infants resulting in increased survival of newborns with morbidities such as perinatal asphyxia, respiratory distress syndrome (RDS), hemorrhage periintraventricular (HPIV) infections and necrotizing enterocolitis ${ }^{6}$.

Tracheal intubation and mechanical ventilation for respiratory support is a resource used in the care of preterm infants to reduce the mortality in this population. However, tracheal intubation can lead to damage such as glottis stenosis and tracheal stenosis ${ }^{7,8}$. Oral lesions occur mainly in the buccal mucosa, the hypoglossal nerve, lingual nerve, fractured teeth, defective development of enamel (DDE), disruption of the dental crown, and dental malformations ${ }^{9-14}$.

Some precautions are recommended to minimize the effect of the tracheal tube into the oral cavity, such as: a) to define a switch back and forth during intubation, and b) to evaluate continuously the quality of the fixing and stabilization the head of the child in order to decrease the tube displacement preventing accidental extubation ${ }^{15}$.

Tracheal intubation trauma to oral tissues occurs during elevation of the laryngoscope blade in order to displace the tongue back to expose the pharyngeal region. In this handling, the correct is to raise the blade toward the end of the laryngoscope, avoiding pressure on the movement of the laryngoscope weighbridge, lips and teeth ${ }^{16,17}$. This swing movement pulls the cable with the laryngoscope in the direction of who is intubating. It is considered a incorrect move. When this maneuver is performed in children, it exerts excessive pressure on the gum pads and can affect the primary teeth that are in the development phase of crown ${ }^{17}$.

In newborns, access to the trachea may be slightly more difficult than in adults because of anatomic variations of the tongue that is larger in relation to the mandible and the larynx that is more cephalic than in children older than 4 months old. The epiglottis is in the level of the first cervical vertebra and by the first 6 months it moves down, getting at that time of the third vertebra. The epiglottis is stiff and narrow and is bent in reversed U-shape. These anatomical variations among newborns, children and adults are easily overcome by the use of the straight blade Miller laryngoscope which shows the $\operatorname{laryn} \mathrm{x}^{18}$.

Physicians should be aware of to the possible trauma in the oral cavity in face of the lack of protection of bone deciduous tooth germs at birth, which must be avoided 
during the maneuvers of delivery, intubation and mechanical ventilation ${ }^{19-21}$.

The prevalence of DDE is higher among premature infants intubated ( $85 \%)$ when compared with nonintubated (27\%). The forces exerted by the laryngoscope in traumatic swing maneuvers during direct laryngoscopy on the oral mucosa are considered the main causes of trauma to the tooth buds of maxillary incisors in development ${ }^{14,22}$. These complications can be avoided if an accurate technique is used during laryngoscopy for tracheal intubation ${ }^{23}$.

Although the enamel defects have been observed among premature newborns before the 80's, few studies have been done on the relationship between intubation, intubation time, prematurity and enamel defects in deciduous teeth.

The purpose of this study was to investigate the relationship between tracheal intubation during the neonatal period and the prevalence of enamel defects in primary teeth of children born prematurely.

\section{MATERIAL AND METHODS}

This study was approved by the Ethics in Research Involving Human Subjects of the Hospital de Clínicas (HC), Universidade Federal do Paraná - UFPR (Protocol Number: 1615.032/2008).

The proposed design for the study was characterized as observational, prospective and analytical. The study was conducted at the Clinic of Child Care Risk of the Hospital de Clínicas, Universidade Federal do Paraná UFPR between 2008 and 2010. These units are accredited by the manager of the Unified Health System / Brazil as a tertiary center for treatment of preterm infants and risk and serve predominantly children born in the Maternity Service of HC, which is one of the centers for high-pregnancies risk in Curitiba and metropolitan region with has an average of 2,178 births/year.

The sample was considered a sample of convenience of a reference hospital for high-risk pregnancy. Two hundred and forty-four preterm infants (gestational ages between 23-36 weeks and chronological age between 2 and 4 years) with the presence of all eight primary incisors in the oral cavity and that were intubated or not in the neonatal period were examined. Individuals with genetic syndromes, orofacial malformations, absence of one of the previous eight primary incisors due to trauma, extraction or delayed eruption and tracheal intubation after the neonatal period were excluded. A total of 157 children were selected: a) Group IOT - composed by 77 premature infants intubated and, b) Group NIOT - composed by 80 children not intubated in the neonatal period.

Oral examination was carried out under artificial light with the use of sterile gauze and wooden spatula. The type of DDE and its location were recorded on data sheet. The data regarding the indication of IOT and residence time of the tracheal tube among the newborns that were intubated were collected. Data were obtained by interview and retrospective analysis of medical records to evaluate the influence of maternal conditions in DDE. The following information was collected: prenatal care, type and cause of delivery, the presence of maternal diseases and drugs used during pregnancy. The variables related to children were birth weight, gestational age, sex, and presence of diseases during the neonatal period and use of drugs in this period. In order to avoid biased results, it was not known to the researcher, at the time of the oral examination, if the child had been intubated or not in the neonatal period. All enrolled patients were evaluated by protocol especially designed for the study and the data were entered into a spreadsheet.

The data were analyzed by Student's t parametric and nonparametric Mann-Whitney test. The estimate of the difference between categorical variables was performed using the Fisher test and Chi-square test with minimum significance level of $5 \%$, with minimal threshold test of $85 \%$. The sample size was calculated considering error of type II to type $10 \%$, with an estimated power of at least $90 \%$.

\section{RESULTS}

Of the 244 examined children, 157 were selected, considering the inclusion criteria. Eighty-seven patients were excluded because of their age at examination, 6 to 18 months, and three deciduous teeth in average.

The children studied had a mean birth weight of $1656.3 \pm 627.8 \mathrm{~g}$, gestational age of $31.7 \pm 2.7$ weeks and chronological age of $2.2 \pm 0.6$ years. There was a predominance of males ( $59.2 \%$ of the sample).

The studied children had significant differences regarding the parameters of prematurity with a mean gestational age 30.6 weeks, compared to children, who were not intubated, an average of 32.8 weeks. The mean chronological age at the time of dental examination of the IOT group was $2.2 \pm 0.6$ years and $2.2 \pm 0.7$ years for the NIOT. There was no difference between IOT and NIOT children in relation to gender $(P=0.71)$.

$97 \%$ of mothers performed care prenatal monitoring the prenatal in the IOT group and $96.1 \%$ of mothers in the NIOT group during the neonatal period $(P=0.86)$.

The idiopathic preterm labor was the main cause of premature birth ( $50.6 \%$ versus $60.0 \%$ ) between groups of children IOT and NIOT. Twins were significantly more frequent in NIOT (33.7\%), compared to $18.2 \%$ in the IOT group ( $P=0.04)$. The premature removal of placenta was 6.5 times higher among IOT children when compared with NIOT children.

The prevalent diseases among the mothers of both groups were: smoking, hypertensive disorders, urinary tract infection and diabetes mellitus, with no statistically significant differences between groups (Table 1). However, significant differences in the frequency of absence of disease during pregnancy, $27.5 \%$ of mothers NIOT group and $12.9 \%$ in mothers IOT group $(P=0.04)$.

The correlation between maternal disease and defective enamel showed no statistically significant differences between the mother's diseases in this study with 
Table 1. Comparison between mother's diseases in iot and niot groups during pregnancy.

\begin{tabular}{lrcc}
\hline DISEASES & \% IOT $(\mathrm{n}=77)$ & \% NIOT $(\mathrm{n}=80)$ & $P$ value \\
\hline Smoking & 42.9 & 57.1 & 0.96 \\
Hypertensive disorders & 38.9 & 34.2 & 0.65 \\
Urinary tract infection & 35.1 & 21.2 & 0.08 \\
Diabetes mellitus & 9.1 & 11.2 & 0.85 \\
\hline
\end{tabular}

Table 2. Comparison between maternal disease in pregnancy and children with enamel defect.

\begin{tabular}{|c|c|c|c|c|c|c|}
\hline \multirow{2}{*}{ DISEASES } & \multicolumn{2}{|c|}{ normal enamel } & \multicolumn{2}{|c|}{ Defective enamel } & \multirow{2}{*}{ chi-squared } & \multirow{2}{*}{$P$ value } \\
\hline & No disease & With disease & No disease & With disease & & \\
\hline Hypertensive disorders & 69 & 36 & 30 & 21 & 0.703 & 0.402 \\
\hline Diabetes mellitus & 101 & 5 & 46 & 5 & 1.494 & 0.222 \\
\hline Urinary tract infection & 78 & 28 & 40 & 11 & 0.433 & 0.510 \\
\hline Smoking & 103 & 3 & 47 & 4 & 2.031 & 0.154 \\
\hline
\end{tabular}

Table 3. Drugs used by mothers of intubated and not intubated children.

\begin{tabular}{lccc}
\hline \multicolumn{1}{c}{ DRUGS } & \% IOT $(\mathrm{n}=77)$ & \% NIOT $(\mathrm{n}=80)$ & $P$ value \\
\hline Anti-hypertensive & 38.9 & 35.0 & 0.73 \\
Antimicrobial & 32.5 & 16.2 & 0.03 \\
Insulin & 7.8 & 8.7 & 0.94 \\
Antidepressants / anxiolytics & 3.9 & 1.25 & 0.58 \\
Anti-inflammatory & 1.3 & 3.75 & 0.64 \\
\hline
\end{tabular}

enamel defects in deciduous teeth of premature evaluated (Table 2).

The drugs recommended for treating the main complications experienced by pregnant women were anti-hypertensive and antibiotics (Table 3). The anti-hypertensive drugs were used in $38.9 \%$ of mothers of IOT children and $35.0 \%$ of NIOT children's mothers. There was a statistically significant difference between the frequencies of antimicrobial use among groups of mothers $(32.5 \%$ IOT versus NIOT $16.2 \%, P=0.03$ ). However, no statistically significant difference between antimicrobial use by mothers during pregnancy and the frequency of enamel defects among premature infants studied (chi-squared $=$ 1.117, $P=0.291)$.

Neonatal jaundice was the prevalent disease among groups of children IOT (96.1\%) and NIOT (90.0\%). Table 4 shows the major morbidity of children IOT and NIOT. The IOT newborns had higher frequency of apnea, respiratory distress syndrome (RDS), sepsis, ductus arteriosus persistence (PDA), intraventricular hemorrhage (HPIV); and osteopenia of prematurity and broncho-pulmonary mild/severe.

The recommended drugs for the IOT and NIOT children's diseases belong to different pharmacological groups. There were statistically significant differences in frequency of use of piperacillin and tazobactam, ampicillin, cefepime, teicoplanin and phenobarbital, with more frequent use in the IOT group (Table 5). Of 157 infants, 136 had taken antibiotics in the neonatal period, 73 preterm IOT and 63 NIOT. There was no statistically significant difference between the frequency of use of an- timicrobials comparing children IOT with enamel defects (32.4\%) and children IOT with normal enamel (67.6\%).

Tracheal intubation was recommended to $74.02 \%$ of children with apnea, with RDS 57.14\%, 53.24\% with sepsis, APC 14.28\%, $12.98 \%$ and $15.58 \%$ with PVIVH with meconium aspiration syndrome or preoperatively.

There were no significant differences, in relation to gestational age, birth weight and chronological age at the time of dental examination, in the group of premature infants intubated between children with DDE and intubated with normal enamel. There was a statistically significant difference regarding gender, more often in females among children intubated with $\operatorname{DDE}(52.3 \%, P=0.04)$ of normal enamel. $97.7 \%$ of mothers of children intubated with DDE and $93.9 \%$ with normal enamel performed prenatal care.

There was a statistically significant difference between the time that children remained intubated, when comparing the groups with and without DDE. Children with DDE had a median intubation time of 3.5 days, significantly higher than the group without DDE, 2 days $(P=0.01)$.

There was no statistically significant difference between the frequencies of diseases in pregnant mothers without children intubated with DDE (9.1\%) and intubated with normal enamel $(8.2 \%)$, and no statistically significant difference between the frequencies of drug use in during pregnancy in mothers of children intubated with DDE and normal enamel.

The most prevalent morbidity among children intubated with DDE (97.7\%) and normal enamel (93.9\%) was neonatal jaundice, followed by apnea, RDS, sepsis, PDA, HPIV, osteopenia of prematurity and broncho-pulmonary 
Table 4. Comparison of IOT and NIOT groups diseases presented in the period.

\begin{tabular}{lccc}
\hline DISEASE & IOT $(\mathrm{n}=77)$ & NIOT $(\mathrm{n}=80)$ & $P$ value \\
\hline Jaundice & 96.1 & 90 & 0.24 \\
Apnea & 74.0 & 26.2 & 0.00 \\
RDS & 57.1 & 28.7 & 0.00 \\
Sepsis & 53.2 & 13.7 & 0.00 \\
PCA & 14.3 & 3.75 & 0.04 \\
HPIV & 12.9 & 2.5 & 0.03 \\
Necrotizing enterocolitis & 11.7 & 10 & 0.93 \\
Osteopenia of prematurity & 10.4 & 1.25 & 0.03 \\
Broncho-pulmonary mild/severe & 7.8 & 0 & 0.03 \\
Hypoglycemia & 6.5 & 13.7 & 0.21 \\
Gastroschisis & 3.9 & 0 & 0.23 \\
\hline
\end{tabular}

Table 5. Comparison between iot and niot groups regarding to the drugs used in the neonatal period.

\begin{tabular}{lccc}
\hline DRUGS & \% IOT $(\mathrm{n}=77)$ & \% NIOT $(\mathrm{n}=80)$ & $P$ value \\
\hline Anti-inflammatory & 3.9 & 3.7 & 0.96 \\
Vitamin A and D, folic acid and ferrous sulfate & 98.7 & 100 & 0.31 \\
Furosemide & 15.6 & 6.2 & 0.06 \\
Anti-fungal & 5.2 & 0 & 0.04 \\
Antibiotics & 84.4 & 68.7 & 0.02 \\
Syrup tricalcium & 12.9 & 2.5 & 0.01 \\
Sildenafil & 9.1 & 0 & 0.006 \\
Phenobarbital & 11.7 & 0 & 0.002 \\
Surfactant & 40.3 & 0 & $<0.001$ \\
Methylxanthines & 16.9 & 0 & $<0.001$ \\
Dopamine & 22.1 & 1.2 & $<0.001$ \\
\hline
\end{tabular}

mild / severe. There was no statistically significant difference between the frequency of apnea, RDS, sepsis, PDA, HPIV, osteopenia of prematurity and broncho-pulmonary mild / severe between DDE and IOT with normal enamel.

Among all drugs used by IOT, there was only statistically significant difference in frequency of use of phenobarbital with greater frequency among children intubated with DDE, $P=0.04$. These children had an average of two teeth affected by DDE, and the left side of the upper incisor teeth was the most affected.

The variable duration of intubation was related to the probability of occurrence of DDE $(P<0.001)$, i.e., the greater the number of days intubated, the greater the chance of DDE. The limit of the \% DDE for varying days of intubation tending to zero is $40 \%$ (Fig. 1). From the 157 infants studied, 65 were extremely preterm and 92 late premature. The likelihood of premature DDE between 157 was inversely proportional to the gestational age (Fig. 2). However, when only children who were intubated in the neonatal period $(n=77)$, it was observed that there was no relationship between the probability of DDE and gestational age (Fig. 3) $(P=0.56)$.

From the 51 children who had DDE, 44 children were intubated in the neonatal period and 7 children were not intubated in the neonatal period. From the 106 children with normal enamel, 33 and 73 were children IOT and NIOT. The relationship between child, IOT and NIOT, and DDE are illustrated in chart 14. The frequency of DDE was much higher among children IOT when compared with children NIOT. The reverse is observed in relation to the normal enamel when children NIOT showed higher frequency than the IOT (Fig. 4).

In the seven children NIOT who had primary teeth with DDE, the defects were distributed as follows: enamel hypoplasia occurred in $28.6 \%$, enamel hypomineralization in $28.6 \%$ and the association between hypoplasia and hypomineralization in $42.8 \%$. Among the 44 children IOT who had deciduous teeth with DDE, the defects were distributed as follows: enamel hypoplasia occurred in $70.5 \%$, enamel hypomineralization in $11.3 \%$ and the association between hypoplasia and hypomineralization in $18.2 \%$.

From the 177 teeth affected by DDE among the 44 children NIOT and seven IOT, the upper incisors showed a higher frequency $(80.2 \%)$ of DDE when compared to the lower incisors (19.8\%). The upper left central incisor (61), the left maxillary lateral incisor (62) and the maxillary right central incisor (51) were the most affected teeth (Fig. 5). 


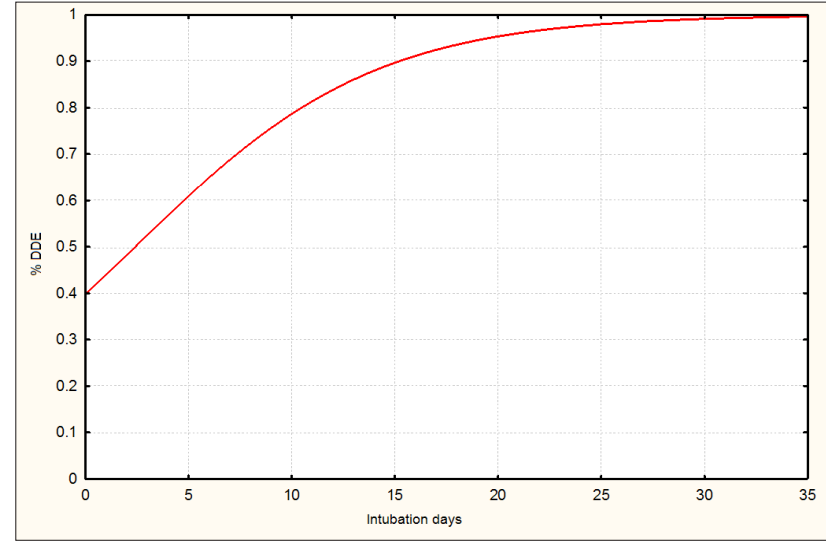

Fig. 1. Relationship between time of intubation and DDE.

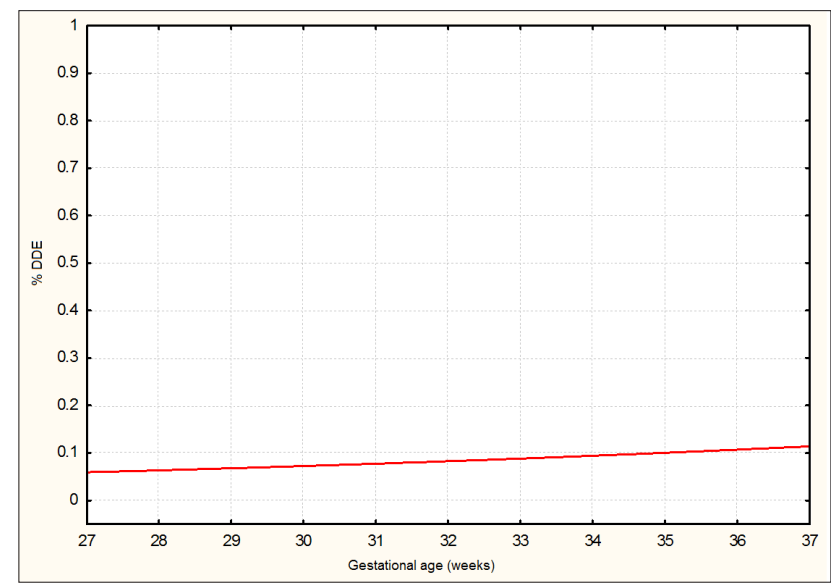

Fig. 3. DDE likelihood in the group of intubated children and the relationship with gestational age.

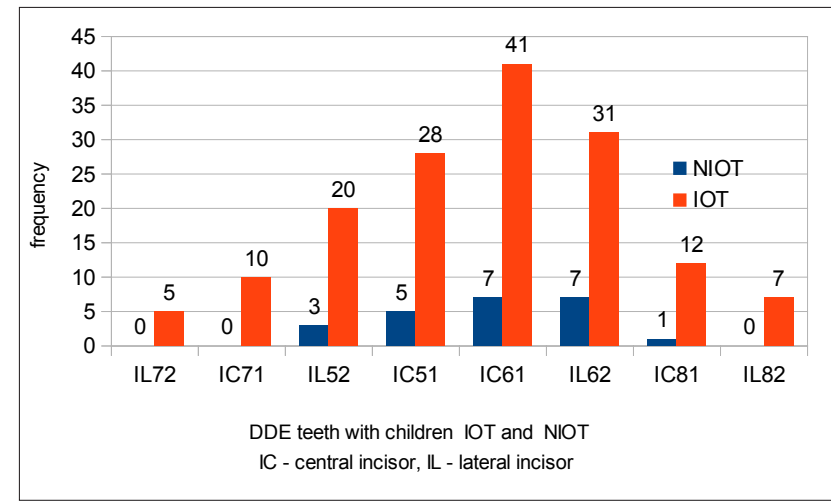

Fig. 5. Distribution of DDE in teeth of premature IOT and NIOT.

Hypoplasia was manifested in different ways in affected teeth. There were cases of loss of part of the crown of teeth (Fig. 6 and 7) or presence of ridges and troughs (Fig. 8).

\section{DISCUSSION}

Enamel defects in primary dentition of premature infants have been studied since the 70 s. These studies

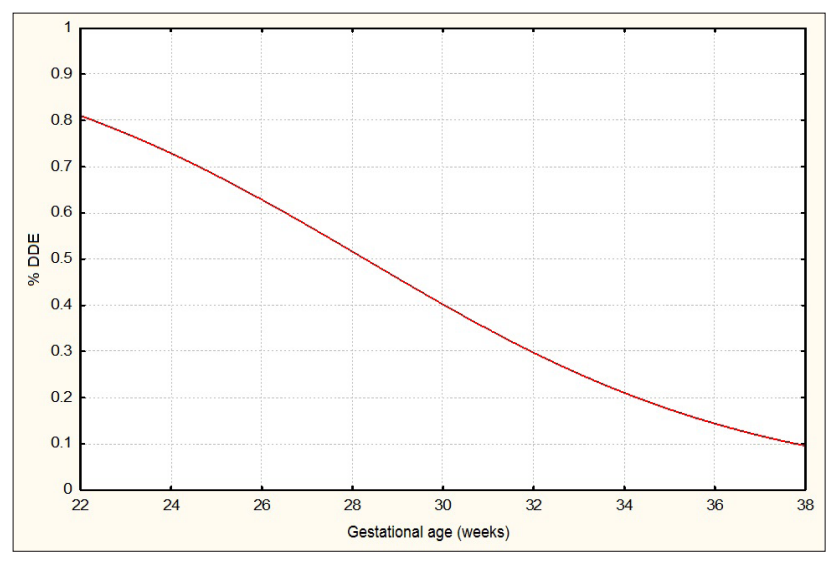

Fig. 2. Relationship between likelihood of premature DDE and gestational age.

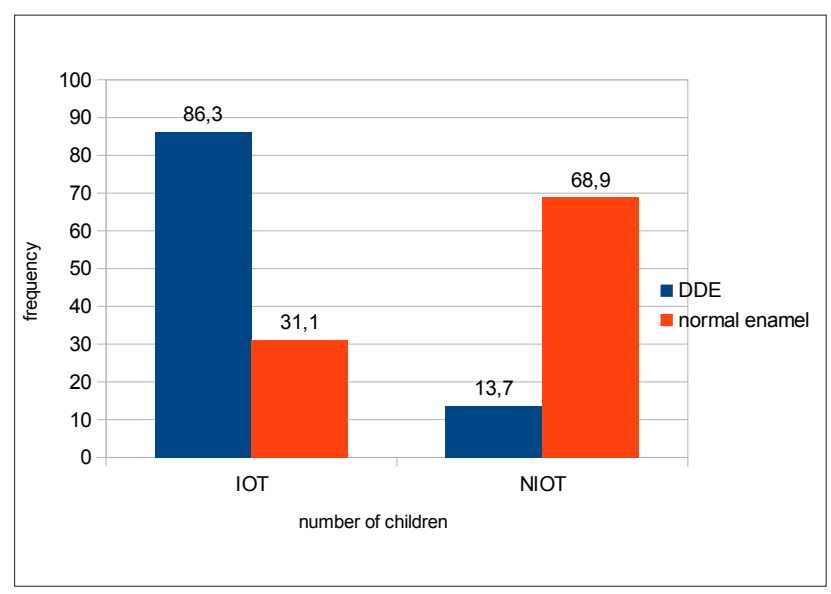

Fig. 4. Frequency of DDE and normal enamel in premature IOT and NIOT

showed a prevalence ranging from $26 \%$ to $96 \%$ DDE. Many of these studies showed the tracheal intubation as an important risk factor in the determination of DDE in deciduous teeth of children born preterm ${ }^{11,22,24-26}$.

The birth of a premature child corresponds in odontogenesis to the late bell stage, time in which the deciduous teeth are in the stage of mineralization of the organic matrix of tooth enamel. Any disturbance by local or systemic factors may affect the germ of the deciduous teeth and determine the DDE. These defects are manifested clinically as hypoplasia or hypomineralization enamel or association among them ${ }^{27-30}$.

In this study, maternal history of hypertension, urinary tract infection, diabetes mellitus, smoking and use of antimicrobial drugs during pregnancy had no relationship to the development of enamel defects among 157 infants studied. Children, IOT and NIOT, showed statistically significant differences between the parameters of prematurity. However, no significantly difference in relation to the prenatal care, maternal complications and basic drugs used by mothers during pregnancy.

Premature children had, in average, a smaller number of primary teeth among children aged 6 to 24 months 


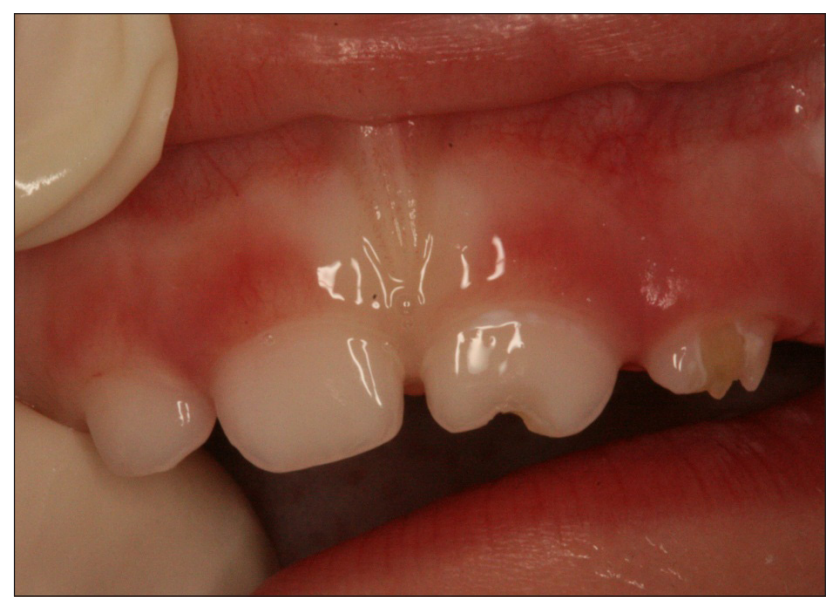

Fig. 6. Enamel hypoplasia of the left maxillary incisors in a child intubated for 15 days.

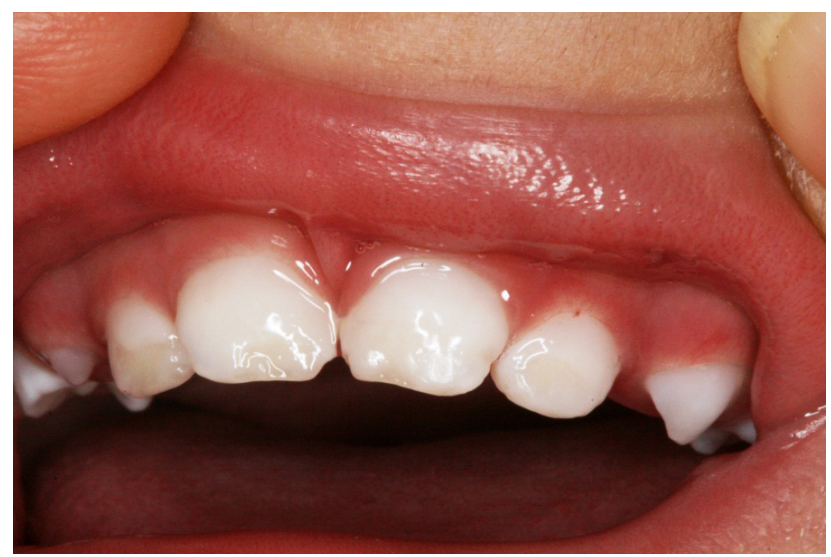

Fig. 7. Enamel hypoplasia of the deciduous incisors in a child intubated for 30 days.

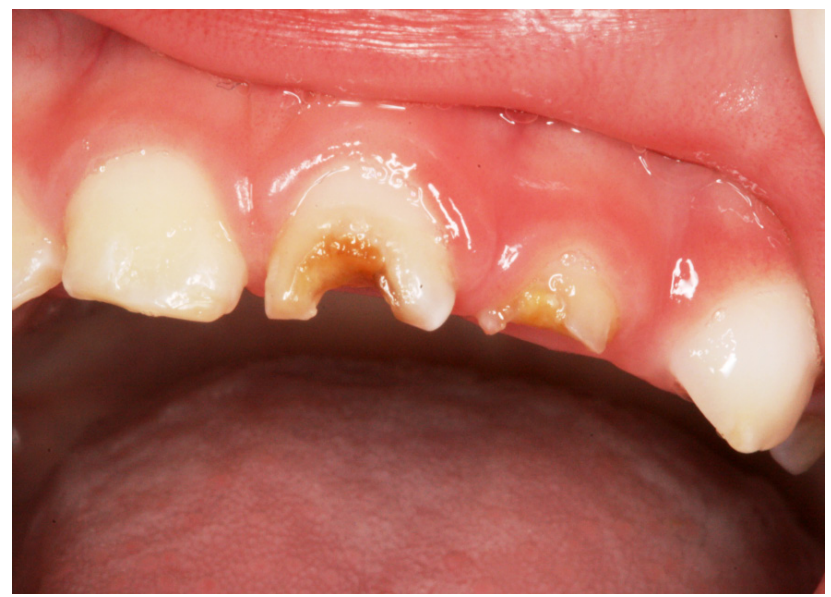

Fig. 8. Enamel hypoplasia in all upper deciduous incisors medium between third and incisal edge in a child intubated for two days.

when compared with children born at term ${ }^{12}$. The explanation lies in the fact that the maxillary central incisor teeth of premature infants present a reduced percentage of mineralization in the organic matrix at birth ${ }^{31}$. In these teeth neonatal line lies between the incisal edge and the middle line of the crown ${ }^{24}$. However, when gestational age is corrected, the delay in the eruption is not observed ${ }^{32,33}$. In this study 87 infants were excluded due to delayed eruption of deciduous anterior teeth upon clinical examination.

As regards to the prematurity, children in this study were classified as preterm, average weight of $1656.3 \pm$ $627.8 \mathrm{~g}$, gestational age was $31.7 \pm 2.7$ (31.3 to 32.1 ) weeks examination and chronological age of $2.2 \pm 0.6$ years. Classification recommended by the American Academy of Pediatrics for every infant born alive ${ }^{34-36}$.

In this study, idiopathic preterm delivery by cesarean section was the main cause of premature birth and IOT and NIOT. Preterm birth occurred regardless of whether their mothers have made the monitoring of prenatal care. This finding is in agreement with Salge et al. ${ }^{37}$.

Tracheal intubation in this study was recommended for children with apnea, RDS, sepsis, PDA, HPIV, meconium aspiration syndrome and preoperative. These morbidities and complications are the main causes of the indication for intubation in the neonatal period ${ }^{6}$.

There was a statistically significant difference between the time that children remained intubated, when comparing the IOT groups with and without DDE. Children with DDE IOT had a median duration of the intubation of 3.5 days, which was significantly higher in the group without DDE, which was two days $(P=0.01)$.

The DDE between the intubated infant had a higher frequency than the children with normal enamel. However, the probability of DDE was inversely proportional to gestational age among the 157 premature studied. When analyzing the frequency of premature considering the DDE gestational age between 23 and 31 weeks, from those with 32 to 36 weeks the ratio of DDE and normal enamel shows no statistically significant difference $(P=0.017)$. We found that premature infants with gestational age between 23 to 31 weeks $(63.6 \%)$ were intubated longer than those with gestational ages from 32 to 36 weeks $(36.4 \%)$. This explains why the prevalence of DDE was inversely proportional to gestational age, since the IOT formed the largest group of preterm infants with DDE, as showed by the results of the study group of children intubated, where there was no relationship between the probability of DDE and gestational age $(P=0.16)$.

The statistical analysis showed that the variable, duration of intubation, was related to the probability of occurrence of DDE, ie, the greater the number of days the child is intubated greater the chance of DDE. The threshold value of zero days of intubation was $40 \%$ for occurrence of DDE. This value indicates the existence of a specific cause for the occasional occurrence of DDE at the time of execution of the technique of intubation ${ }^{38,39}$. It was possibly caused by the turning movement of the laryngoscope weighbridge causing pressure on the gingival mucosa, lips and teeth ${ }^{17}$ contributing as an important local factor for the enamel defects observed in the upper deciduous incisors. Seow et al. ${ }^{22}$ and Vello et al.$^{39}$ correlated the presence of DDE with the intubation time and showed that this time is variable, ranging from one to three days. 
The present study examined other parameters that may be related to the DDE: (i) maternal complications during pregnancy, (ii) use of drugs during pregnancy, (iii) morbidities presented by the $\mathrm{RN}$ in the neonatal period and (iv) drugs used by $\mathrm{RN}$ in the neonatal period. No significant associations were found between these parameters and the frequency of enamel defects in this population.

In children IOT enamel hypoplasia mainly affected the upper left incisor, left maxillary lateral incisor and maxillary right central incisor. These teeth are in the area corresponding to the side of the laryngoscope position during insertion of the orotracheal tube. The technique TI recommends that the laryngoscope blade should move toward the midline and be raised without changing the direction of the axis of the cable pair to avoid the pressure and movement of the laryngoscope weighbridge on the lips and teeth ${ }^{16,17}$. The inability to see the larynx usually leads to multiple or prolonged attempts at laryngoscopy with increasing pressure force. This increased pressure force is associated with lesions of the esophagus and larynx, injury to the teeth, unsaturation, hemodynamic instability and intensive unplanned care. Cooper ${ }^{40}$, in a historical review of developments in the techniques of laryngoscopy, stressed the need for improved management techniques to reduce airway and forced multiple laryngoscopy.

\section{CONCLUSIONS}

1. Tracheal intubation is the leading cause of enamel defects in deciduous anterior teeth from intubated premature infants in the neonatal period. And the longer the period of time the child is intubated greater chance of developing dental enamel defect.

2. The prevalence of enamel defects in preterm infants increases with decreasing gestational age and the use of tracheal intubation increases with decreasing gestational age.

3. The upper right central incisor, lateral incisor and upper left are the teeth most affected by defective enamel. These teeth are located in the region of the laryngoscope pressure, the toggle motion during intubation.

4. The enamel hypoplasia is the most prevalent enamel defect among premature infants intubated in the neonatal period. Furthermore, the associated enamel hypoplasia and hypomineralization defect are more prevalent among infants not intubated in the neonatal period.

\section{REFERENCES}

1. Brito ASJ, Matsuo T, Gonzales MR, Carvalho ABR, Ferrari LSL. Score CRIB, peso ao nascer e idade gestacional na avaliação do risco de mortalidade neonatal. Rev Saúde Pública 2003;37(5):597-602.

2. Guimarães LC. Apoio social e prematuridade em puérperas de baixo peso. Dissertation (Enfermagem) - Universidade Federal do Estado do Rio de Janeiro, Rio de Janeiro, 2010.
3. Silva RCAF. Mortalidade perinatal em hospital terciário da região norte do Brasil. 90 f. Dissertation (Ciências da Saúde) - Universidade de Brasília, 2011.

4. Wood NS. Neurologic and developmental disability after extremely Preterm birth. N Engl J Med 2000;343(6):378-84.

5. Koldewijn K, Wolj MJ, van Wassenaer A, Meijssen D, van Sonderen $L$, van Baar A, Beelen A, Nollet F, Kok J. The infant behavioral assessment and intervention program for very low birth weight infants at 6 months corrected age. J Pediat 2009;154(1):33-8.

6. Almeida MFB, Guinsburg R. Programa de reanimação neonatal da sociedade brasileira de pediatria: condutas 2011. Coordenação Geral do Programa de Reanimação Neonatal da Sociedade Brasileira de Pediatria e Membros do International Liaison Committee on Resuscitation (ILCOR), 2011. 27 p. (http://www.sbp.com.br/pdfs/ PRN-SBP-ReanimacaNeonatal-2011-24jan11.pdf).

7. Barbosa AL, Campos ACS, Chaves EMC. Complicações não clinicas da ventilação mecânica: ênfase no cuidado de enfermagem neonatal. Acta Paul Enferm 2006;9(4):439-43.

8. Jaber S, Amraoui J, Lefrant J, Arich C, Cohendy R, Landreau L, Calvet X, Capdevila X, Mahata A, Eledjam J. Clinical practice and risk factors for immediate complications of endotracheal intubation in the intensive care unit: a prospective, multiple-center study. Crit Care Med 2006;34(9):2355-61.

9. Fadavi S, Punwani IC, Adeni S, Vidyasagar D. Eruption patern in he primary dentition of premature low-birth-weight children. J Dent Child 1992;59(2):420-4.

10. Kropa DE, Davis EL. Prevalence of oral defects among neonatally intubated 3 to 5 and 7 to 10 years old children. Pediatr Dent 1991;13(6):349-55.

11. Aine L, Backstrom MC, Maki R, Kuusela AL, Koivisto AM, Ikonen RS, Maki M. Enamel defects in primary and permanent teeth of children born prematurely. J Oral Pathol Med 2000; 29(8):403-9.

12. Seow WK. Effects of preterm birth on oral growth and development. Aust Dental J 1997;42(2):85-91.

13. Hohff A, Heike R, Ulrike E, Erik H. Palatal development of preterm and low birthweight infants compared to term infants - What do we know? Part 2: The palate of the preterm/low birthweight infant. Head Face Med 2005;1(9):1-2.

14. Takaoka LAMV, Goulart AL, Kopelman BI. Enamel defects in the complete primary dentition of children born at term and preterm. Pediatr Dent 2011;33(2):171-6.

15. Quinn W, Sandifer RRT, Goldsmith JP. Pulmonary care. In: Goldsmith JP, Karotkin EH. Assisted ventilation of the neonate. 3. ed. Philadelphia: Saunders Company, 1996. p. 101-124.

16. American Heart Association (AHA); American Academy of Pediatrics (AAP). American Heart Association Guidelines for Cardiopulmonary Resuscitation (CPR) and Emergency Cardiovascular Care (ECC) of Pediatric and Neonatal Patients: Pediatric Advanced Life Support. Pediatrics 2006;117(5):258.

17. Matsumoto T, Carvalho WB. Tracheal intubation. J Pediatr 2007;83(2);83-90.

18. Walker RWM. Management of the difficult airway in children. J Royal Soc Med 2001;94(1):341-4.

19. Moylan, FMB, Seldin EB, Shannon DC, Todres IDV. Defective primary dentition in survivors of neonatal mechanical ventilation. J Pediatr 1980;96(1):106-8.

20. Seow WK. Enamel hypoplasia in the primary dentition: a review. J Dent Child 1991;58(6):441-52.

21. Machado FC, Ribeiro RA. Defeito do esmalte e cárie dentária em crianças prematuras e/ou de baixo peso ao nascimento. Pesq Bras Odontoped Clin Integr 2004;4(3):243-7.

22. Seow WK, Brown JP, Tudehope DI, O'Callaghan M. Developmental defects in the primary dentition of low birth-weight infants: adverse effects of laryngoscopy and prolonged endotracheal intubation. Pediatr Dent 1984;6(1):28-31.

23. Corvo MAA, Inacio A, Mello MBC, Eckley CA, Duprat AC. Complicações extralaríngeas das cirurgias por laringoscopia direta de suspensão. Rev Bras Otorrinolaringol 2007;73(6):727-32.

24. Johnsen D, Krejci C, Hack M, Fanaroff A. Distribution of enamel defects and the association with respiratory distress in very low birth weight infants. J Dent Res 1984;63(1):59-64.

25. Hanser-Ducatti C, Puppin-Rontani RM, Bastos HD, Carvalho LR. Relação entre nutrição e alteração do esmalte dental em escolares Botucatu-SP. Cien Odontol Bras 2004;7(1):84-92. 
26. Barbosa DML, Lemos LVFM, Banzi ECF, Myaki SI. Prevalência de hipoplasia do esmalte em dentes decíduos de crianças nascidas prematuras. Rev Odontol UNESP 2008;37(3):261-5.

27. McDonald RE, Avery DR, Dean JA. Dentistry for the child and adolescent. 9th ed. St. Louis: Mosby; 2010.

28. Norén JG. Enamel structure in decisuous teeth from low birth weight infants. ACTA Odontol Scand 1983;41(6):355-62.

29. Neville BW. Oral \& Maxillofacial Pathology. 3rd ed. Philadelphia; Toronto: W.B. Saunders; 2008.

30. Nanci A, Ten Cate A.R. Ten Cate's oral histology: development, structure, and function. 7th ed. St. Louis: Mosby; 2007.

31. Allan JH. Investigations into the mineralization pattern of human dental enamel. J Dent Res 1958;38(1):1096-107.

32. Almonaitiene R., Balciuniene I, Tutkuviene, J. Factors influencing permanent teeth eruption. Part one - general factors. Stomatologija, Baltic Dental and Maxillofacial Journal 2010;12(3):67-72.

33. Peedikayil, F.C. Delayed tooth eruption. J Dent 2011;1(4):81-6.

34. Schieve, LA, Meikle SF, Ferre C, Peterson HB, Jeng G, Wilcox LS. Low and very low birth weight in infants conceived with use of assisted reproductive technology. N Engl J Med 2002;346(10):731-7.
35. Mclntire DD, Bloom S, Casey BM, Leveno KJ. Birth weight in relation to morbidity and mortality among newborn infants. New Engl J Med 1999;340(16):1234-8.

36. Gomella TL, Cunningham MD, Eyal FG, Zenk KE, Neonatology:Management, Procedures, On-Call Problems Diseases, and Drugs, 5th edition, Ed. McGraw-Hill, 2004

37. Salge AKM, Vieira AVC, Aguiar AKA, Lobo SF, Xavier RM, Zatta LT, Correa RRM, Siqueira KM. Fatores maternos e neonatais associados à prematuridade. Rev Eletr Enf 2009;11(3):642-6.

38. Eastman DL. Dental outcomes of preterm infants. Newborn Infant Nurs Rev 2003;3(3):93-8.

39. Velló MA, Martínez-Costa C, Catalá M, Fons J, Brines J, GuijarroMartínez R. Prenatal and neonatal risk factors for the development of enamel defects in low birth weight children. Oral Dis 2010;16(3):25762.

40. Cooper RM. Laryngoscopy - Its past and future. Can J Anaesth 2004:51(6):1-5. 